\section{Pitfalls of antinuclear antibody detection in systemic lupus erythematosus: the positive experience of a national multicentre study}

The recent paper by Pisetsky et al, ${ }^{1}$ which already elicited some debate ${ }^{23}$ reported data on the use of antinuclear antibodies (ANA) detection in patients with systemic lupus erythematosus (SLE) in the real life and raised concerns on the usefulness of the assays because of the significant percentage of samples tested negative for ANA in spite of the use of well-validated assays and the inclusion of patients with an established diagnosis. This finding may have negative implications both for the correct classification and the inclusion in clinical trials.

We report here a multicentre study carried out by an Italian interdisciplinary group (Forum Interdisciplinare per la Ricerca sulle Malattie Autoimmuni) for the validation of new automated reading systems for ANA detection by indirect immunofluorescence on HEp-2 cells (HEp-2 IFA). Ninety-one patients with well-estab-

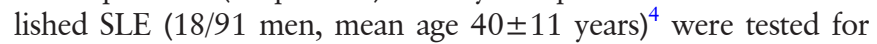
ANA, anti-extractable nuclear antigens (ENA) and anti-double stranded (ds)-DNA. Manual HEp-2 IFA (with different HEp-2 commercial preparations including HEp-2000) was performed at the recruiting centre and then sent to two core labs where three different automated ANA reading systems were used with the manufacturers' cell substrate (1:80 screening dilution). Moreover, all the samples were tested by two commercial connective tissue disease (CTD) screening solid phase arrays (SPA). We found almost a perfect agreement between manual and automated ANA reading. As expected, SPA displayed a lower sensitivity (table 1 ). ${ }^{5}$ By testing all the samples with both HEp-2 IFA and SPA we reached 100\% sensitivity. One sample only tested positive for DFS70 but the positivity was associated with anti-ENA antibodies, a combination that can be found in systemic autoimmune rheumatic diseases. ${ }^{6}$ The detection of antibodies against ENA and dsDNA was performed at the recruiting centres by using different commercial kits. The percentages of patients positive for anti-ENA and anti-dsDNA were similar to those of the Pisetsky's series making the two cohorts comparable.

The results of our study show that: (1) ANA is a hallmark of established SLE; (2) ANA detection by different commercially available kits is reliable in a multicentre setting and the variability linked to the single operator does not seem to be a critical issue. The CTD screening SPAs display a lower sensitivity than HEp-2 IFA likely due to the limited number of autoantigens, however they can offer an additional diagnostic value when carried out together with IFA. ${ }^{5}$

Francesca Pregnolato, ${ }^{1}$ Maria Orietta Borghi, ${ }^{1,2}$ Pier Luigi Meroni, ${ }^{1}$ Forum Interdisciplinare per la Ricerca sulle Malattie Autoimmuni (FIRMA) Study Group

${ }^{1}$ Immunorheumatology Research Laboratory, IRCCS Istituto Auxologico Italiano, Milan, Italy

2Department of Clinical Sciences and Community Health, University of Milan, Milan, Italy
Correspondence to Professor Pier Luigi Meroni, Immunorheumatology Research Laboratory, IRCCS Istituto Auxologico Italiano, Milan 20095, Italy; pierluigi.meroni@unimi.it

Collaborators Claudia Alpini, Alessia Alunno, Maria Romana Bacarelli, Andrea Doria, Sergio Finazzi, Franco Franceschini, Roberto Gerli, Anna Ghirardello, Luigi Giovannelli, Maria Grazia Giudizi, Milvia Lotzniker, Paola Migliorini, Gabriella Morozzi, Federico Pratesi, Antonella Radice, Valeria Riccieri, Amelia Ruffatti, Paola Sabatini, Giandomenico Sebastiani, Renato Alberto Sinico, Angela Tincani, Marta Tonello.

Contributors FP contributed to data acquisition, analysis and interpretation. FP, MOB and PLM gave substantial contributions to the conception of the work and drafting of the letter, had full access to all of the data in the study and take responsibility for the integrity of the data and the accuracy of the data analysis. The FIRMA Study Group provided patients, collected data and critically reviewed the study proposal. All the contributors read and approved the manuscript.

Funding The authors have not declared a specific grant for this research from any funding agency in the public, commercial or not-for-profit sectors.

Competing interests None declared.

Patient consent Obtained.

Ethics approval Ethics Committee of Istituto Auxologico Italiano, 22-07-2010.

Provenance and peer review Not commissioned; internally peer reviewed.

(C) Article author(s) (or their employer(s) unless otherwise stated in the text of the article) 2019. All rights reserved. No commercial use is permitted unless otherwise expressly granted.

\section{Check for updates}

To cite Pregnolato F, Borghi MO, Meroni PL, et al. Ann Rheum Dis 2019;78:e50.

Received 3 April 2018

Revised 11 April 2018

Accepted 12 April 2018

Published Online First 25 April 2018

\section{Linked}

- http://dx.doi.org/10.1136/annrheumdis-2018-213582

Ann Rheum Dis 2019;78:e50. doi:10.1136/annrheumdis-2018-213516

\section{REFERENCES}

1 Pisetsky DS, Spencer DM, Lipsky PE, et al. Assay variation in the detection of antinuclear antibodies in the sera of patients with established SLE. Ann Rheum Dis 2018;77:911-3.

2 Mahler M. Lack of standardisation of ANA and implications for drug development and precision medicine. Ann Rheum Dis 2019;78:e33.

3 Pisetsky DS, Spencer DM, Lipsky PE, et al. Response to: 'Lack of standardization of ANA and implications for drug development and precision medicine' by Mahler. Ann Rheum Dis 2019;78:e34.

4 Petri M, Orbai AM, Alarcón GS, et al. Derivation and validation of the Systemic Lupus International Collaborating Clinics classification criteria for systemic lupus erythematosus. Arthritis Rheum 2012;64:2677-86.

5 Claessens J, Belmondo T, De Langhe E, et al. Solid phase assays versus automated indirect immunofluorescence for detection of antinuclear antibodies. Autoimmun Rev 2018. doi: 10.1016/j.autrev.2018.03.002. [Epub ahead of print 8 Mar 2018].

6 Conrad K, Röber N, Andrade LE, et al. The clinical relevance of Anti-DFS70 autoantibodies. Clin Rev Allergy Immunol 2017;52:202-16.

Table 1 ANA detection

\begin{tabular}{|c|c|c|c|c|c|c|c|c|}
\hline \multirow[b]{2}{*}{ Test results } & \multicolumn{4}{|l|}{ HEp-2 IFA } & \multicolumn{2}{|l|}{ CTD SPA* } & \multirow[b]{2}{*}{ Anti-ENA } & \multirow[b]{2}{*}{ Anti-dsDNA } \\
\hline & Manual & Auto $1 \dagger$ & Auto 2 & Auto 3 & $\mathrm{a}$ & b & & \\
\hline Positive \% (n/N) & $100(91 / 91)$ & $100(91 / 91)$ & $98(89 / 91)$ & $99(90 / 91)$ & $88(80 / 91)$ & $91(83 / 91)$ & $45(40 / 89)$ & $59(54 / 91)$ \\
\hline Negative \% (n/N) & $0(0 / 91)$ & $0(0 / 0)$ & $2(2 / 91)$ & $1(1 / 91)$ & $12(11 / 91)$ & $9(8 / 91)$ & $55(49 / 89)$ & $41(37 / 91)$ \\
\hline
\end{tabular}

*CTD SPA, connective tissue diseases screening solid phase assay; (a) Quanta Flash CTD screen plus, INOVA Diagnostics: recombinant Scl-70, Jo-1, SSA/Ro 52, SSA/Ro 60, SSB/La, centromere A and B, RNA Pol III, Mi-2, Ku, Th/To, PCNA, native Sm and RNP, synthetic Pm/Scl and ribosomal-P peptides and synthetic dsDNA; (b) ELiA CTD screen, Thermo Fisher: dsDNA, SSA/Ro 52, SSA/Ro 60, SSB/La, U1-RNP (RNP-70, A, C), Sm, centromere B, Jo-1, Scl-70, Rib-P, fibrillarin, RNA Pol III, PM-Scl, PCNA and Mi-2, all recombinant except native purified dsDNA.

†Automated reading systems: (1) AKLIDES, Medipan GMBH; (2) NOVA-View, INOVA Diagnostics; (3) G-Sight, Menarini Diagnostics.

ANA, anti-nuclear antibodies; ENA, extractable nuclear antigen; HEp-2 IFA, indirect immunofluorescence on HEp-2 cells. 